\title{
Cloning, expression and purification of the anion exchanger 1 homologue from the basidiomycete Phanerochaete chrysosporium.
}

\section{AUTHOR(S):}

Tokuda, Natsuko; Igarashi, Kiyohiko; Shimamura, Tatsuro; Yurugi-Kobayashi, Takami; Shiroishi, Mitsunori; Ito, Keisuke; Sugawara, Taishi; ... Nomura, Norimichi; Iwata, So; Kobayashi, Takuya

\section{CITATION:}

Tokuda, Natsuko .... [et al]. Cloning, expression and purification of the anion exchanger 1 homologue from the basidiomycete Phanerochaete chrysosporium.. Protein expression and purification 2011, 79(1): 81-87

\section{ISSUE DATE:}

2011-09

\section{URL:}

http://hdl.handle.net/2433/143680

\section{RIGHT:}

(C) 2011 Elsevier Inc.; This is not the published version. Please cite only the published version.; この論文は出版社版でありません。引用の際に は出版社版をご確認ご利用ください。 
$+^{*}$ Article title

\section{Cloning, expression and purification of the anion exchanger 1 homologue from the basidiomycete Phanerochaete chrysosporium.}

Natsuko Tokuda ${ }^{\text {a, }}{ }^{1}$, Kiyohiko Igarashi $^{\text {b, }}{ }^{1}$, Tatsuro Shimamura ${ }^{\text {c, 1, Takami }}$ Yurugi-Kobayashic, Mitsunori Shiroishic, Keisuke Ito ${ }^{\mathrm{d}}$, Taishi Sugawara ${ }^{\mathrm{d}}$, Hidetsugu

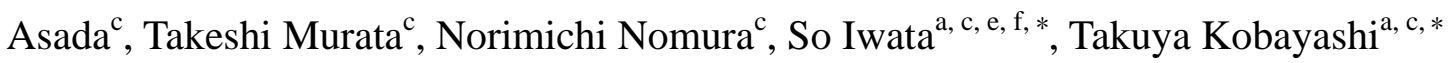

${ }^{a}$ Department of Medical Chemistry, Kyoto University Faculty of Medicine, Konoe-cho, Yoshida, Sakyo-ku, Kyoto 606-8501, Japan.

${ }^{b}$ Department of Biomaterials Sciences, Graduate School of Agricultural and Life Sciences, The University of Tokyo, Bunkyo-ku, Tokyo 113-8657, Japan.

${ }^{c}$ Iwata Human Receptor Crystallography project, ERATO, JST, Konoe-cho, Yoshida, Sakyo-ku, Kyoto 606-8501, Japan.

${ }^{d}$ Department of Applied Biological Chemistry, Graduate School of Agricultural and Life Sciences, The University of Tokyo, Bunkyo-ku, Tokyo 113-8657, Japan.

${ }^{e}$ RIKEN Genomic Sciences Center, 1-7-22 Suehiro-cho, Tsurumi, Yokohama 230-0045, Japan.

${ }^{f}$ Membrane Protein Crystallography Group, Division of Molecular Biosciences, Imperial College London, SW7 2AZ, UK,

Key words: Anion exchanger; Pichia pastoris; cloning; purification; Phanerochaete chrysosporium

*Corresponding author: Takuya Kobayashi

Fax: +81-75-753-4660

Tel: +81-75-753-4386

E-mail: t-coba@mfour.med.kyoto-u.ac.jp

*Corresponding author: So Iwata

Fax: +81-75-751-8263

Tel: +81-75-753-4372

E-mail: s.iwata@mfour.med.kyoto-u.ac.jp 
${ }^{1}$ These authors contributed equally to this work.

\begin{abstract}
Anion exchangers are membrane proteins that have been identified in a wide variety of species, where they transport $\mathrm{Cl}^{-}$and $\mathrm{HCO}_{3}{ }^{-}$across the cell membrane. In this study, we cloned an anion-exchange protein from the genome of the basidiomycete Phanerochaete chrysosporium (PcAEP). PcAEP is a 618-amino acid protein that is homologous to the human anion exchanger (AE1) with $22.9 \%$ identity and $40.3 \%$ similarity. PcAEP was overexpressed by introducing the PcAEP gene into the genome of Pichia pastoris. As a result, PcAEP localized in the membrane of $P$. pastoris and was solubilized successfully by n-dodecyl- $\beta$-D-maltoside. His-tagged PcAEP was purified as a single band on SDS-PAGE using immobilized metal affinity chromatography and gel filtration chromatography. Purified PcAEP was found to bind to SITS, an inhibitor of the AE family, suggesting that the purified protein is folded properly. PcAEP expressed and purified using the present system could be useful for biological and structural studies of the anion exchange family of proteins.
\end{abstract}




\section{Introduction}

Anion exchangers are membrane proteins that have been identified in a wide variety of species (e.g., human [1], mouse [2], rat [3], chicken [4], trout [5], yeast [6], and fungi [7]). Anion exchanger 1 (AE1) transports $\mathrm{Cl}^{-}$and $\mathrm{HCO}_{3}{ }^{-}$across the membrane to maintain intracellular $\mathrm{pH}$ levels [8]. In human, AE1 is found primarily in erythrocytes and kidney. Human AE1 is a glycoprotein comprised of 2 distinct domains: the cytoplasmic $\mathrm{N}$-terminal $\sim 40 \mathrm{kDa}$ domain contains binding sites for cytoskeletal and cytoplasmic proteins, and the membrane-embedded C-terminal $\sim 55 \mathrm{kDa}$ domain mediates anion exchange [9-11]. Mutations in the C-terminal domain are known to cause diseases such as human distal renal tubular acidosis [12].

AE1 transports several kinds of anions with a variety of sizes and charge distributions. Human AE1 is known to transport $\mathrm{SO}_{4}{ }^{2-}, \mathrm{PO}_{4}{ }^{3-}, \mathrm{Br}^{-}$, and $\mathrm{I}^{-}$, as well as $\mathrm{Cl}^{-}$ and $\mathrm{HCO}_{3}^{-}[13,14]$. This activity can be inhibited specifically by stilbene disulfonate inhibitors [14]. To elucidate these mechanisms of anion exchange in detail, it is essential to know structural information about AE1. However, the crystal structure of AE1 remains unknown, due to the difficulties in its crystallization. Generally, large quantities of pure protein are required to obtain diffracting crystals. Recombinant human AE1 has been expressed at relatively high levels in the yeast Saccharomyces cerevisiae [15]; however, the purity of the recombinant protein was insufficient for crystallization. A His-tagged form of the AE1 homologue in S. cerevisiae (YNL275w) also has been expressed in the yeast, but the resulting expression levels were low [6].

In this report, we successfully constructed an overexpression system for the

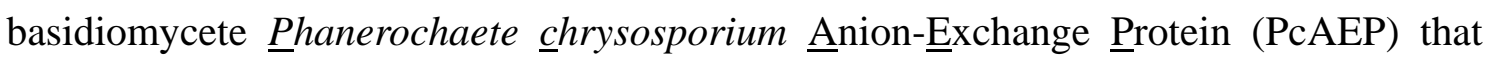
shows sequence similarities to human AE1 and yeast YNL275w. His-tagged PcAEP was highly expressed in Pichia pastoris and purified by metal affinity chromatography and gel filtration. The structural integrity of the purified protein was assessed by the binding of a stilbene disulfonate AE1 inhibitor, SITS (4-acetamido-4'-isothiocyano-2,2'-stilbene disulphonic acid) [14].

\section{Materials and Methods}

Strains

P. chrysosporium strain K-3 [16] was used as a source for the target gene. Escherichia coli strain JM109 (Takara Bio, Shiga, Japan) and P. pastoris strain 
SMD1168H (Invitrogen, Carlsbad, CA) were used for subcloning and heterologous production of the recombinant protein, respectively.

Cloning of the cDNA encoding PcAEP

P. chrysosporium was grown in Kremer and Wood medium [17] containing 2\% glucose or cellulose (CF11; Whatman, Fairfield, NJ, USA) as the sole carbon source, as described previously [18]. After culturing for $3 \mathrm{~d}$, mycelia were collected using a glass filter membrane (ADVANTEC ${ }^{\circledR}$ GA-100; Toyo Roshi Kaisha, Tokyo, Japan) and frozen in liquid nitrogen. Total RNA was extracted from approximately $200 \mathrm{mg}$ of frozen mycelial powder using ISOGEN (Nippon Gene, Tokyo, Japan). The mRNA was purified from $1 \mu \mathrm{g}$ of total RNA extracted with Oligotex ${ }^{\mathrm{TM}_{-}} \mathrm{dT} 30<$ Super $>$ (Takara Bio) using ReverTraAce (Toyobo, Osaka, Japan) and a 3' RACE adaptor primer (Invitrogen). First-strand cDNA was synthesized from the mRNA.

The gene encoding PcAEP was identified in a search of the P. chrysosporium genome database (http://genome.jgi-psf.org/Phchr1/Phchr1.home.html) using the amino acid sequence of YNL275w, an anion exchanger from $S$. cerevisiae (NCBI accession number $\underline{\mathbf{Z 7 1 5 5 1}}$ ). Oligonucleotide primers for the amplification of the cDNA fragment encoding PcAEP (Pcaep) were designed based on the genomic sequence (e_gwh2.17.21.1), as follows: Pcaep-F: 5'-TTTATGTCAA ACGTTACATC GCGCACC-3', and Pcaep-R: 5'-TTTCTAGTGT ATGCCCCCGA CGGATTC-3'. PCR was performed using KOD-Plus (version 2; Toyobo). PCR products were cloned using a Zero Blunt ${ }^{\circledR}$ TOPO $^{\circledR}$ PCR cloning kit and E. coli JM109. Sequencing was performed using a BigDye Terminator v3.1 cycle sequencing kit with an automated DNA sequencer (ABI PRISM 3100 Genetic analyzer, Applied Biosystems, Foster, CA, USA). The nucleotide sequence was submitted to the DDBJ/EMBL/GenBank databases under accession number $\underline{\mathbf{A B 4 4 4 8 5 3}}$.

Transformation of cDNA encoding PcAEP

The PcAEP gene was isolated from the TOPO vector by digestion with SfuI and NotI. The isolated fragment was ligated into the pPICZ A plasmid (Invitrogen) pretreated with $S f u$ I and NotI. FLAG- and His-tags were introduced at the C-terminus of PcAEP. The pPICZ A plasmid containing PcAEP was linearized with PmeI (New England Biolabs, Ipswich, MA, USA). The linearized plasmid was transformed into the genome of the methylotropic yeast $P$. pastoris SMD1168H by electroporation using the Gene Pulser Xcell system (Bio-Rad, Hercules, CA). 
Transformants were plated on YPDS plates (1\% yeast extract, $2 \%$ peptone, $2 \%$ dextrose, $1 \mathrm{M}$ sorbitol, and $2 \%$ agar) containing $100 \mu \mathrm{g} / \mathrm{mL}$ zeocin and were screened by zeocin resistance. Positive clones were cultured and induced to produce PcAEP. Protein expression was examined by Western blotting. Selected transformants highly expressing PcAEP were stored as glycerol stocks at $-80^{\circ} \mathrm{C}$.

\section{Culture of PcAEP transformants}

Selected clones were grown in BMGY (Buffered Glycerol-complex Medium, $1 \%$ yeast extract, $2 \%$ peptone, $100 \mathrm{mM}$ potassium phosphate, $\mathrm{pH} 6.0,1.34 \%$ yeast nitrogen base without amino acids, $4 \times 10^{-5} \%$ biotin and $1 \%$ glycerol) at $30{ }^{\circ} \mathrm{C}$ overnight. Cultures were diluted 4-fold in BMGY and cultured for 4-6 h. The cells were harvested by centrifugation at $4000 \mathrm{~g}$ for $15 \mathrm{~min}$ and induced to express PcAEP in BMMY (Buffered Methanol-complex Medium, 1\% yeast extract, 2\% peptone, $100 \mathrm{mM}$ potassium phosphate, $\mathrm{pH} 7.0,1.34 \%$ yeast nitrogen base without amino acids, $4 \times 10^{-5} \%$ biotin, $3 \%$ DMSO, $4 \%$ histidine, and $0.5 \%$ methanol) at $20{ }^{\circ} \mathrm{C}$ for $20 \mathrm{~h}$. The cells were harvested by centrifugation at $4000 \mathrm{~g}$ for $15 \mathrm{~min}$.

Different temperatures $\left(20\right.$ and $\left.30^{\circ} \mathrm{C}\right)$ and induction times $(20,40$, or $60 \mathrm{~h})$ were tested to optimize the culture conditions.

Immunofluorescence microscopy

Unless otherwise noted, the following steps were performed at room temperature. PcAEP-expressing cells were washed with PBS buffer ( $\mathrm{pH} 7.4$ ), fixed with $4 \%$ paraformaldehyde for $2 \mathrm{~h}$, and washed thrice with PBS. The fixed cells were gently incubated with $0.2 \%$ zymolyase-100T (Seikagaku Biobusiness Corp., Tokyo, Japan) at $35{ }^{\circ} \mathrm{C}$ for $2 \mathrm{~h}$ to remove the cell wall. The cells were washed with PBS, followed by permeabilization with 3\% NP-40 and 10\% DMSO in PBS for $30 \mathrm{~min}$. Permeabilized cells were blocked overnight with $5 \%$ BSA in PBS at $4{ }^{\circ} \mathrm{C}$. BSA-treated cells were incubated with primary antibody (1:300 anti-polyhistidine mAb; Sigma-Aldrich) followed by secondary antibody (1:300 Alexa Fluor 488; Invitrogen) in PBS containing $5 \%$ BSA for $1.5 \mathrm{~h}$. The cells were washed with PBS, attached to a slide glass, and observed with a spectral confocal scanning system (LEICA, Solms, Germany).

\section{Membrane preparation, solubilization and protein purification}

Cell pellets $(1 \mathrm{~g})$ were resuspended in $3 \mathrm{~mL}$ of buffer $\mathrm{A}(50 \mathrm{mM}$ sodium phosphate, $\mathrm{pH} 7.4,100 \mathrm{mM} \mathrm{NaCl}, 5 \%$ glycerol, $2 \mathrm{mM}$ EDTA, and protease inhibitor cocktail (Complete EDTA-free, Roche Applied Science, Mannheim, Germany)). Cells 
were disrupted by vigorous agitation in the presence of glass beads at $4{ }^{\circ} \mathrm{C}$ for $2 \mathrm{~h}$. After centrifugation at $2,000 \mathrm{~g}$ for $10 \mathrm{~min}$ to remove cell debris, the supernatant was centrifuged at $100,000 \mathrm{~g}$ for $45 \mathrm{~min}$. The membrane pellet was collected and homogenized in buffer B $(50 \mathrm{mM}$ Tris- $\mathrm{HCl}, \mathrm{pH} 8.0,120 \mathrm{mM} \mathrm{NaCl}, 20 \%$ glycerol, and Complete EDTA-free protease inhibitor cocktail). The final protein concentration, estimated by bicinchoninic acid (BCA) assay (Pierce, Rockford, IL, USA), was adjusted to $10 \mathrm{mg} / \mathrm{mL}$ with buffer $\mathrm{C}$ (20 mM Hepes, $\mathrm{pH} 7.0,500 \mathrm{mM} \mathrm{NaCl}, 30 \%$ glycerol).

The membranes were solubilized with $1 \%$ n-dodecyl- $\beta$-D-maltoside (DDM, Anatrace, OH, USA) and $0.2 \%$ cholesteryl hemisuccinate (Sigma-Aldrich) at $4{ }^{\circ} \mathrm{C}$ for 1 h. The solution was centrifuged at $100,000 \mathrm{~g}$ for $45 \mathrm{~min}$ to remove insoluble material. Solubilized protein $(300 \mathrm{mg})$ was mixed with $1 \mathrm{~mL}$ of TALON ${ }^{\mathrm{TM}}$ metal affinity resin (Clontech, Palo Alto, CA, USA) in $20 \mathrm{mM}$ imidazole. After incubation on a rotary wheel at $4{ }^{\circ} \mathrm{C}$ overnight, the resin was collected by centrifugation and washed with 50 $\mathrm{mL}$ of buffer D (20 mM Hepes, pH 7.0, $250 \mathrm{mM} \mathrm{NaCl}, 10 \%$ glycerol, 0.05\% DDM and $0.01 \%$ cholesteryl hemisuccinate) containing $20 \mathrm{mM}$ imidazole. Bound proteins were then eluted with $6 \mathrm{~mL}$ of buffer D containing $167 \mathrm{mM}$ imidazole.

The eluted fractions were pooled, concentrated, and loaded onto a Superdex 200 10/300 column (GE Healthcare, Tokyo, Japan). The main peak fractions were loaded onto a second Superdex 200 10/300 column. The fraction corresponding to PcAEP was analyzed by Coomassie staining. At the gel-filtration chromatography step, the column was preequilibrated with the running buffer (20 mM Hepes, $\mathrm{pH} 7.0,150 \mathrm{mM} \mathrm{NaCl}$, $0.05 \% \mathrm{DDM}$ ) and the flow rate was $0.3 \mathrm{~mL} / \mathrm{min}$.

SITS Affi-gel binding assay

A SITS Affi-gel binding assay was performed as described previously $[6,12,19,20]$. Purified $0.1 \mu \mathrm{g} / \mu \mathrm{l}$ PcAEP $(2 \mu \mathrm{L}$ aliquot) was incubated with $50 \mu 1$ SITS Affi-gel resin in $100 \mu \mathrm{L}$ citrate buffer $(0.1 \%$ DDM, $250 \mathrm{mM}$ sodium citrate, $\mathrm{pH} 7.1)$ at $4{ }^{\circ} \mathrm{C}$ for $30 \mathrm{~min}$. The resin was collected by centrifugation and the supernatant (unbound fraction) was removed. The collected resin was washed thrice with $0.5 \mathrm{~mL}$ of citrate buffer. The protein bound to the SITS Affi-gel (bound fraction) was released from the resin with $50 \mu \mathrm{L}$ of SDS sample buffer (Invitrogen) at room temperature. Both unbound and bound fractions were analyzed by Western blotting. 


\section{Results and Discussion}

"Figure 1 near here"

\section{Cloning of PcAEP cDNA encoding PcAEP}

The basidiomycete $P$. chrysosporium was found to carry one gene (e_gwh2.17.21.1) encoding a hypothetical anion exchange protein, as determined in a genome database search of $P$. (http://genome.jgi-psf.org/Phchr1/Phchr1.home.html) [21]. As shown in Fig. 1, PcAEP has homology to human AE1 (band 3) and S. cerevisiae YNL275w [6]. The cDNA of

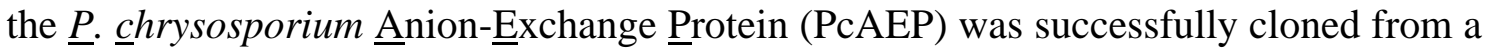
P. chrysosporium cDNA library and consisted of an 1854-nt open reading frame encoding a 618-amino acid protein.

Sequence alignment

A BLAST search of the NCBI database (http://www.ncbi.nlm.nih.gov/blast/Blast.cgi) using the blastp algorithm detected sequences homologous to PcAEP in other species. The polypeptide consists of 618 amino acid residues with an estimated molecular weight of 68,644.55. The amino acid identities and similarities between PcAEP and human AE1 or yeast YNL275w were estimated to be $22.9 \%$ and $37.8 \%$, and $40.3 \%$ and $53.4 \%$, respectively, using the server in http://www.ebi.ac.uk/Tools/emboss/align/index.html.

High-mannose oligosaccharides attach to Asn-X-Thr/Ser (X, any amino acid other than Pro) acceptor sites [22, 23]. PcAEP has 4 Asn-X-Thr/Ser motifs at Asn3, Asn148, Asn295, and Asn344 (Fig. 1). None of these sites correspond to the $\mathrm{N}$-glycosylation site of human AE1 (Asn642). Of the 4 Asn residues, 3 residues (Asn3, Asn148, and Asn344) are conserved in YNL275w, which was characterized previously as a non-glycosylated protein [6]. PcAEP was not detected in glycoprotein staining after electrophoresis (data not shown). Given these considerations, PcAEP is not likely to be glycosylated.

"Figure 2 near here"

\section{PcAEP expression and solubilization}

To confirm the expression of PcAEP in P. pastoris, each fraction was separated by SDS-PAGE and analyzed by Coomassie staining (Fig. 2A) and Western blotting (Fig. 2B). PcAEP was difficult to detect by Coomassie staining. PcAEP was 
detected in the membrane fraction (lane 7) by immunostaining, but not in the soluble fraction (lane 6), indicating that PcAEP is expressed as a membrane protein. A band corresponding to PcAEP was not detected in untransformed cells (lanes 1-4). PcAEP was detected in the solubilized membrane fraction (lane 8), indicating that PcAEP was successfully solubilized by $1 \%$ DDM and $0.2 \%$ cholesteryl hemisuccinate.

"Figure 3 near here"

\section{Optimization of culture conditions}

We examined the effects of the induction temperature and culture time on the PcAEP expression level. Cells were cultured at 20 or $30{ }^{\circ} \mathrm{C}$ for 20,40 , or $60 \mathrm{~h}$ during induction, and the expression levels were analyzed by Western blotting (Fig. 3). PcAEP was degraded under all conditions except for the 20 -h induction at $20{ }^{\circ} \mathrm{C}$. Therefore, this condition was used throughout the paper for the induction of PcAEP expression.

"Fig. 4 near here"

Plasma membrane localization of PcAEP

The plasma membrane localization of PcAEP was confirmed by immunofluorescence. PcAEP was detected at the plasma membrane in transformed cells after permeabilization with NP-40 (Fig. 4e, f), which indicates that PcAEP is properly folded and transported to the plasma membrane. When the cells were immunolabeled without NP-40, no signal could be detected (Fig. 4b, c). These results indicate that the $\mathrm{N}$ - and C-termini of PcAEP locate in the cytosol, similar to the predicted localizations for human AE1 [9] and YNL275w [6].

"Fig. 5, 6, Table1 near here"

\section{Purification of PCAEP}

The solubilized membrane fraction was subjected to TALONTM metal affinity chromatography. Although PcAEP was not detected by Coomassie staining of the solubilized membrane fraction (Fig. 5, lane 1), a major band of PcAEP appeared in the fraction eluted from the TALONTM resin (lane 4). The eluted PcAEP was further purified using Superdex 200 (Fig. 6). Analysis by SDS-PAGE revealed that the main peak corresponded to highly purified PcAEP. As previously reported [25, 26, 27], a monomeric folded protein generally yields a single symmetrical peak that 
may be suitable for crystallization, which suggests that purified PcAEP is a potential target for crystallization.

From a 1-L culture, $1.5 \mathrm{mg}$ of highly purified PcAEP was obtained, which is more than the yields of recombinant human AE1 $(0.7 \mathrm{mg}$ partially purified protein from $1 \mathrm{~L}$ culture) [15] and yeast YNL275w expressed in S. cerevisiae $(0.1 \mathrm{mg}$ from $1 \mathrm{~L}$ culture) [6]. Our expression and purification system for PcAEP will be an important tool for structural studies that require large quantities of the protein.

"Fig. 7 near here"

\section{SITS Affi-gel binding assay}

SITS is a potent inhibitor of anion exchangers. H2DIDS, which is an inhibitor that is similar to SITS, is known to react covalently with K539 and K851 of human AE1 and SITS is presumed to also bind these sites (Fig. 1). To assess the structural integrity of the purified PcAEP, a SITS Affi-gel binding assay was performed for PcAEP, as was done previously for recombinant human AE1 [15] and YNL275w [6]. PcAEP was detected in the bound fraction when incubated with SITS-Affi gel (Fig. 7, lane 4), while the SITS-uncoupled Affi-gel did not bind PcAEP (lane 1). This result indicates that PcAEP binds specifically to SITS and suggests that the purified PcAEP was properly folded.

\section{Conclusion}

In summary, we have successfully cloned and purified PcAEP, an AE1 homologue of the basidiomycete $P$. chrysosporium. The sequence similarity, membrane localization, and SITS-binding ability of PcAEP suggest that this protein is an anion transporter similar to human AE1. P. chrysosporium has a high optimal growth temperature $\left(\sim 39^{\circ} \mathrm{C}\right)[16]$, which suggests that this protein could be more thermostable than AE1 from other species. This finding is intriguing because protein thermostability is an important advantage for protein crystallization. Indeed, structural determination of the turkey $\beta$ 1-adrenergic receptor was successfully completed by improving the thermostability of the receptor through site-directed mutagenesis [28]. A single symmetrical peak in size exclusion chromatography of PcAEP also suggests that it is a good target for crystallization trials.

The expression system described in this study is very suitable for the 
crystallographic study of AE1, as well as for biochemical and biophysical analyses. The AE1 structure determined using our system may not only aid in elucidating the mechanisms underlying AE1 function, but also may be useful for studies of diseases caused by mutations of human AE1.

\section{Acknowledgments}

We thank Ms. S. Funamoto, Ms. N. Katsuta, Ms. T. Uemura and Dr. Y. Nomura for technical assistance, and Ms. C. Fukui for secretarial assistance. This work was supported by a Research Grant from the ERATO Iwata Human Receptor Crystallography Project from the Japan Science and Technology Agency (JST) (to S. I.), in part by a Grant-in-Aid for Scientific Research (B) (20370035 to T. K. and 21370043 to T. S.), by a grant from Takeda Science Foundation (to T.K.), by a grant form the Ichiro Kanehara Foundation (to T. K. and T. S.), by a grant from The Sumitomo Foundation (to T.K.), by a grant from The Mochida Memorial Foundation for Medical and Pharmaceutical Research (to T.K.), by a Research Fellowship from the Uehara Medical Foundation (to T.K.), and by a Challenging Exploratory Research (22659059 to T.K.), and in part by a Research Grant from the Membrane Protein Structure Initiative (MPSi) (to S. I.).

\section{References}

[1] Lux, S. E., John, K. M., Kopito, R. R., Lodish, H. F,. Cloning and characterization of band 3, the human erythrocyte anion-exchange protein (AE1), Prot Natl Acad Sci USA. 86 (1989) 9089-9093.

[2] Kopito, R. R., Lodish, H. F, Primary structure and transmembrane orientation of the murine anion exchange protein, Nature. 316 (1985) 234-238.

[3] Kudrycki KE, Shull GE, Primary structure of the rat kidney band 3 anion exchange protein deduced from a cDNA. J Biol Chem. 264 (1989) 8185-8192.

[4] Cox JV, Lazarides E, Alternative primary structures in the transmembrane domain of the chicken erythroid anion transporter, Mol Cell Biol. 8 (1988) 1327-1335.

[5] Hübner S, Michel F, Rudloff V, Appelhans H, Amino acid sequence of band-3 protein from rainbow trout erythrocytes derived from cDNA, Biochem J. 285 (1992) 17-23.

[6] Zhao R, Reithmeier RA, Expression and characterization of the anion transporter 
homologue YNL275w in Saccharomyces cerevisiae, Am J Physiol Cell Physiol. 281( 2001) C33-45.

[7] Martin F, Aerts A, Ahrén D, Brun A, Danchin EG, Duchaussoy F, Gibon J, Kohler A, Lindquist E, Pereda V, Salamov A, Shapiro HJ, Wuyts J, Blaudez D, Buée M, Brokstein P, Canbäck B, Cohen D, Courty PE, Coutinho PM, Delaruelle C, Detter JC, Deveau A, DiFazio S, Duplessis S, Fraissinet-Tachet L, Lucic E, Frey-Klett P, Fourrey C, Feussner I, Gay G, Grimwood J, Hoegger PJ, Jain P, Kilaru S, Labbé J, Lin YC, Legué V, Le Tacon F, Marmeisse R, Melayah D, Montanini B, Muratet M, Nehls U, Niculita-Hirzel H, Oudot-Le Secq MP, Peter M, Quesneville H, Rajashekar B, Reich M, Rouhier N, Schmutz J, Yin T, Chalot M, Henrissat B, Kües U, Lucas S, Van de Peer Y, Podila GK, Polle A, Pukkila PJ, Richardson PM, Rouzé P, Sanders IR, Stajich JE, Tunlid A, Tuskan G, Grigoriev IV, The genome of Laccaria bicolor provides insights into mycorrhizal symbiosis, Nature. 452 (2008) 88-92.

[8] Alper SL, The band 3-related anion exchanger (AE) gene family, Annu Rev Physiol. 53 (1991) 549-564.

[9] Reitheier RA, The erythrocyte anion transporter (band 3), Curr Opin Struct Biol. 3 (1993) 515-523.

[10] Low PS, Structure and function of the cytoplasmic domain of band 3: center of erythrocyte membrane-peripheral protein interactions, Biochim Biochem Acta. 864 (1986) 145-167.

[11] Grinstein S, Ship AN, Rothstein A, Anion transport in relation to proteolitic dissection of band 3 protein, Biochim Biophys Acta. 507 (1978) 294-304.

[12] Jarolim P, Shayakul C, Prabakaran D, Jiang L, Stuart-Tilley A, Rubin HL, Simova S, Zavadil J, Herrin JT, Brouillette J, Somers MJ, Seemanova E, Brugnara C, Guay-Woodford LM, Alper SL, Autosomal dominant distal renal tubular acidosis is associated in three families with heterozygosity for the R589H mutation in the AE1 (band 3) Cl-/HCO3- exchanger, J Biol Chem. 273 (1998) 6380-6388.

[13] N. Hamasaki, Y. Abe, Tanner, M. J, Flexible regions within the membrane-embedded portions of polytopic membrane proteins, Biochemistry. 41 (2002) 3852-3854.

[14] Cabantchik ZI, Greger R, Chemical probes for anion transporters of mammalian cell membranes, Am J Physiol Call Physiol. 262 (1992) C803-C827.

[15] Sekler I, Kopito RR. Casey jR, High level expression, partial purification, and 
functional reconstitution of the human AE1 Anion exchanger in Saccharomyces cerevisiae, J Biol Chem. 270 (1995) 21028-21034.

[16] Johnsrud SC, Eriksson KE, Cross-breeding of selected and mutated homokaryotic strains of Phanerochaete chrysosporium K-3 - New cellulase deficient strains with increased ability to degrade lignin, Appl Microbiol Biotechnol 21 (1985) 320-327.

[17] Kremer, SM, Wood pPM, Evidence that cellobiose oxidase from Phanerochaete chrysosporium is primarily an $\mathrm{Fe}(\mathrm{III})$ reductase. Kinetic comparison with neutrophil NADPH oxidase and yeast flavocytochrome $b_{2}$, Eur J Biochem. 205 (1992) 133-138.

[18] Habu N, Igarashi K, Samejima M, Pettersson B, Eriksson KE, Enhanced production of cellobiose dehydrogenase in cultures of Phanerochaete chrysosporium supplemented with bovine calf serum, Biotechnol Appl Biochem. 26 (1997) 97-102.

[19] Kotaki A, Naoi M, Yagi K, A diaminoatilbene dye as a hydrophobic probe for prorteins, Biochim Biophys Acta. 229 (1971) 547-556.

[20] Pimplikar SW, Reithmeier RA, Affinity chromatography of Band 3, the anion transporter protein of erythrocyte membranes, J Biol Chem. 261 (1986) 9770-9778.

[21] Martinez D, Larrondo LF, Putnam N, Gelpke MD, Huang K, Chapman J, Helfenbein KG, Ramaiya P, Detter JC, Larimer F, Coutinho PM, Henrissat B, Berka R, Cullen D, Rokhsar D, Genome sequence of the lignocelluloses degrading fungus Phanerochaete chrysosporium strain RP78, Nat Biotecnol. 22 (2004) 695-700.

[22] Landolt-Marticorena C, Reithmeier RA, Asparagine-linked oligosaccharides are localized to single extracytosolic segments in multi-span membrane glycoproteins, Biochem J. 302 (1994) 253-260.

[23] Nilsson IM, von Heijne G, Determination of the Distance between the oligosaccharyltransferase active site and the Endoplasmic Reticulum membrane, J Biol C 268 (1993) 5798-5801.

[24] Okubo K, Kang D, Hamasaki N, Jennings ML, Red blood cell band 3. Lysine 539 and lysine 851 react with the same H2DIDS (4,4'-diisothiocyanodihydrostilbene-2,2'-disulfonic acid) molecule, J Biol Chem. 269 (1994) 1918-1926.

[25] Kawate T, Gouaux E, Fluorescence-detection size-exclusion chromatography for precrystallization screening of integral membrane proteins, Structure. 14 (2006) 673-681.

[26] Newstead S, Kim H, von Heijne G, Iwata S, Drew D, High-throughput 
fluorescent-based optimization of eukaryotic membrane protein overexpression and purification in Saccharomyces cerevisiae, Proc Natl Acad Sci U S A. 104 (2007) 13936-13941.

[27] Sugawara T, Ito K, Shiroishi M, Tokuda N, Asada H, Yurugi-Kobayashi T, Shimamura T, Misaka T, Nomura N, Murata T, Abe K, Iwata S, Kobayashi T, Fluorescence-based optimization of human bitter taste receptor expression in Saccharomyces cerevisiae, Biochem Biophys Res Commun. 382 (2009) 704-710.

[28] Warne T, Serrano-Vega MJ, Baker JG, Moukhametzianov R, Edwards PC, Henderson R, Leslie AG, Tate CG, Schertler GF, Structure of a beta(1)-adrenergic G-protein-coupled receptor, Nature. (2008) 486-491. 


\section{Figure Legends}

\section{Fig. 1. Sequence alignment of PcAEP with the C-terminal transmembrane domain} of human erythroid AE1 and yeast YNL275w. Sequences were aligned using the CLUSTALW web server (http://clustalw.ddbj.nig.ac.jp/top-j.html). (*) identical residues, (:) strongly similar residues, and $(\cdot)$ weakly similar residues. The closed arrows indicate putative $\mathrm{N}$-glycosylation acceptor sites $(\mathrm{N}-\mathrm{X}-\mathrm{S} / \mathrm{T}, \mathrm{X} \neq \mathrm{P})$. The open arrow indicates the $\mathrm{N}$-glycosylation acceptor site of human AE1. $\mathrm{H}_{2}$ DIDS-binding lysines in human AE1 are in red [24].

Fig. 2. PcAEP expression. Each lane contains $\sim 20 \mu \mathrm{g}$ of protein, as estimated using a BCA assay. Lanes 1, 5: whole cell extract; Lanes 2, 6: soluble fractions; Lanes 3, 7: membrane fractions; Lanes 4, 8: membrane fractions solubilized with 1\% DDM, $0.2 \%$ cholesteryl hemisuccinate. Lanes 1-4: membranes from untransformed cells; Lanes 5-8: membranes from PcAEP transformed cells. (A) SDS-PAGE analysis. (B) Western blotting. The arrow indicates the band corresponding to the expressed PcAEP.

Fig. 3. Optimization of the culture conditions. Membrane fractions were analyzed by Western blotting with the anti-FLAG-M2 antibody. Each lane contained $\sim 7.5 \mu \mathrm{g}$ of the membrane fraction, as estimated using a BCA assay. Lane 1: $20^{\circ} \mathrm{C}, 20 \mathrm{~h}$; Lane 2: $20^{\circ} \mathrm{C}$, $40 \mathrm{~h}$; Lane 3: $20{ }^{\circ} \mathrm{C}, 60 \mathrm{~h}$; Lane 4: $30{ }^{\circ} \mathrm{C}, 20 \mathrm{~h}$; Lane 5: $30{ }^{\circ} \mathrm{C}, 40 \mathrm{~h}$; and Lane $6: 30^{\circ} \mathrm{C}$, 60 h. Arrow indicates PcAEP.

Fig. 4. Immunofluorescence staining of yeast cells. a-c: Nonpermeabilized cells; d-f: NP-40-permeabilized cells; a, d: Untransformed cells; b, e: N-terminal His-tagged PcAEP-transformed cells; c, f: C-terminal His-tagged PcAEP-transformed cells. Left: Bright-field image; Right: fluorescence image.

Fig. 5. Purification of PcAEP using TALON metal affinity resin. All fractions were analyzed by SDS-PAGE. Lane 1, solubilized membranes with 1\% DDM, $0.2 \%$ cholesteryl hemisuccinate; Lane 2, unbound fraction; Lane 3, wash fraction; and Lane 4, eluted fraction. Arrow indicates PcAEP.

Fig. 6. Purification of TALON-purified PcAEP with gel filtration. SDS-PAGE 
analysis of the main peak corresponding to PcAEP that was eluted from the Superdex 200 column. Arrow indicates the band corresponding to PcAEP.

Fig. 7. SITS Affi-gel binding assay. Purified PcAEP was incubated with SITS Affi-gel. The bound protein was eluted with SDS sample buffer. Lanes 1, 2: PcAEP was incubated with Affi-gel without SITS (negative control). Lanes 3, 4: PcAEP was incubated with SITS Affi-gel. U, unbound fraction; B, bound fraction. 
PCAEP

YNL2 75w

hAE1

PCAEP

YNL2 75w

hAE1

PCAEP

YNL2 75w

hAE1

PCAEP

YNL2 75w

hAE1

PCAEP

YNL275W

hAE1

PCAEP

YNL2 75w

$\mathrm{hAE} 1$

PCAEP

YNL2 75w

hAE1

PCAEP

YNL2 75w

hAE1

PCAEP

YNL2 75w

hAE1

PCAEP

YNL2 75w

hAE1

PCAEP

YNL2 75w

$\mathrm{hAE} 1$

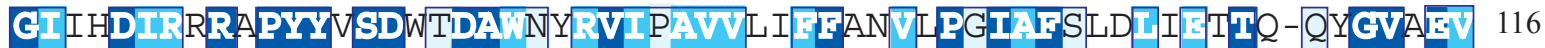

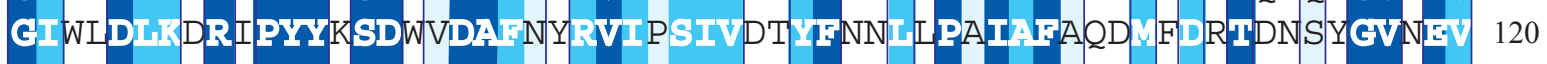

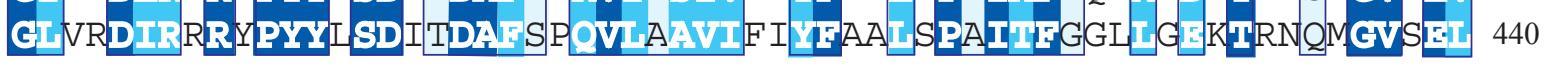

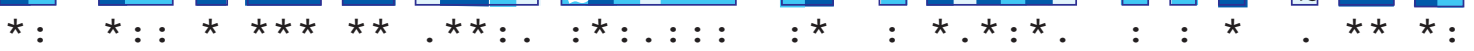

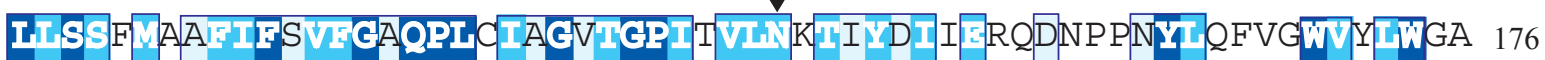

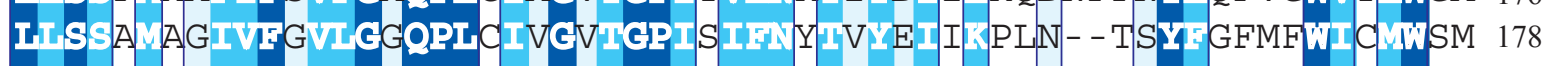

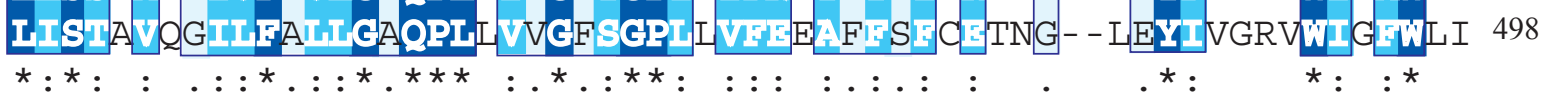

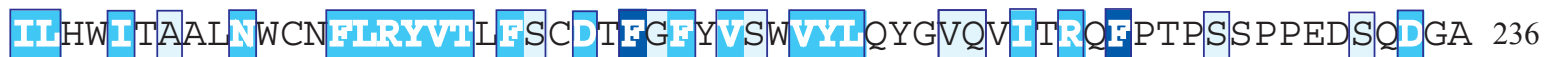

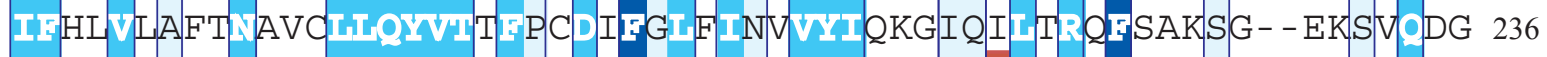

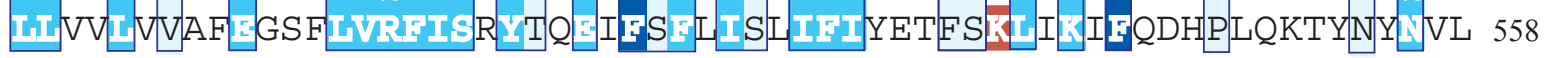

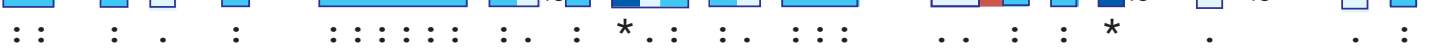

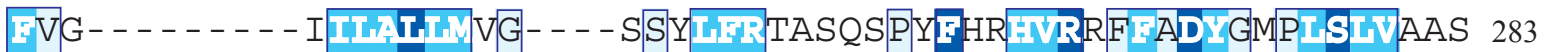

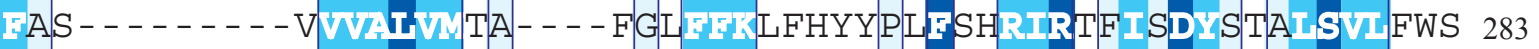

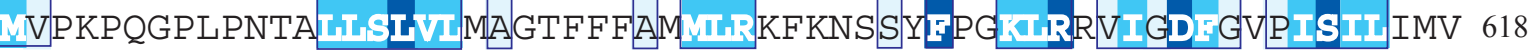
$\therefore$ : $::^{*}:: . \quad$. : : . ${ }^{*}::^{*} . .^{*}: .:^{*}::$

AMAY SFTH GGYLHDV FKK PITKA F P SKVNRPONTWLAYEPI PVKD F I LPFGI F T I 343 LVDF IQDTYTQ LS-VPDGFKVSNSSARGWVIHPLGLRSEFPIWM FA SALPA I F I 677 . . :

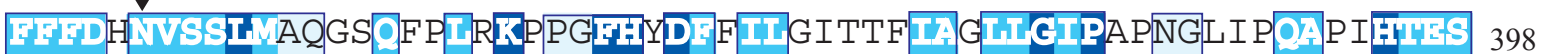

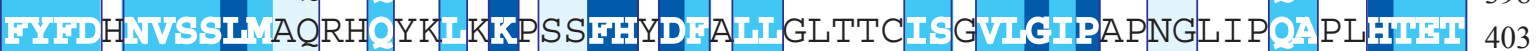

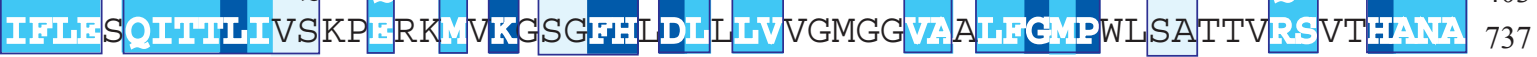
$:::::::^{*}: \ldots \quad: \quad:{ }^{*} \ldots{ }^{*}{ }^{*}::: \quad:: .::^{*} *^{*} \quad$ : $:$ *::

ITMESTHKKLDDIETPSRSREKTPSQPHELGTALAPVHMSRFQEELEPDPTLARDGDGE 458

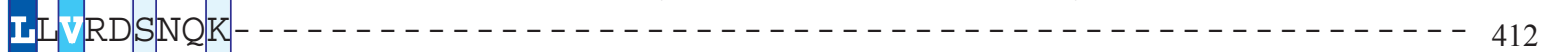

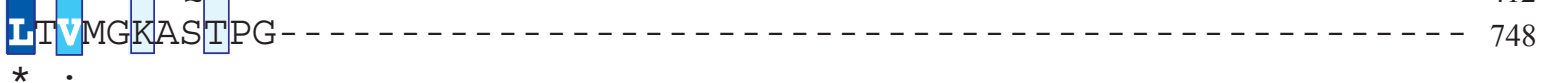

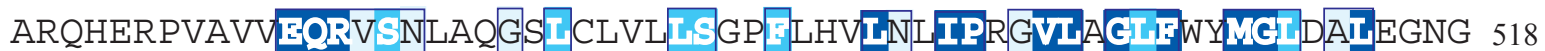

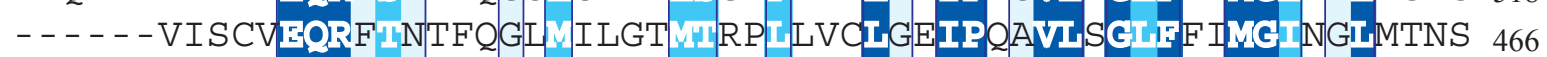

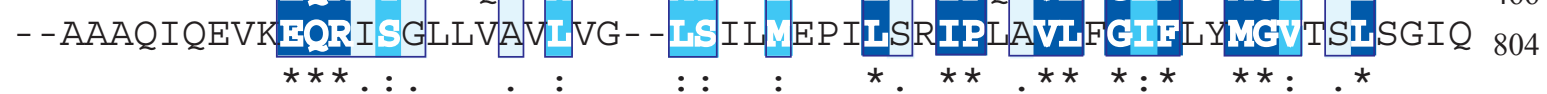

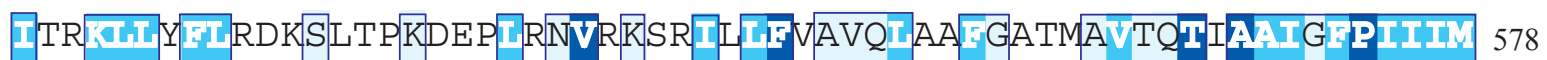

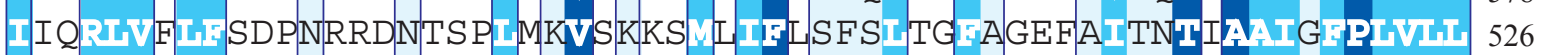

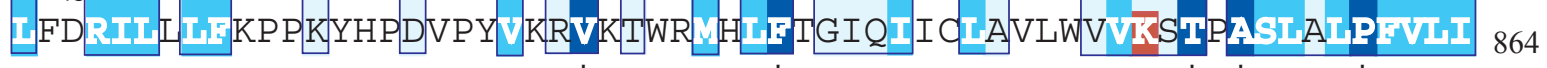

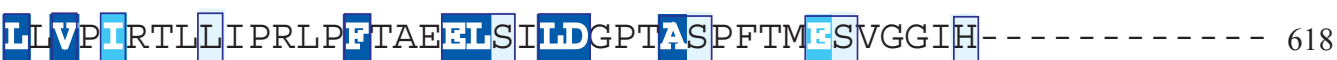
ISVL V S - FSFAYIFPTEEIKITDTNVAQKFTI NLLLENIRDAKFCDKHED 576 UIVP RR-VLLPLIFRNVEIIOUDADDAKATFDLEEGRDEYDEVAMPV - - - 911 


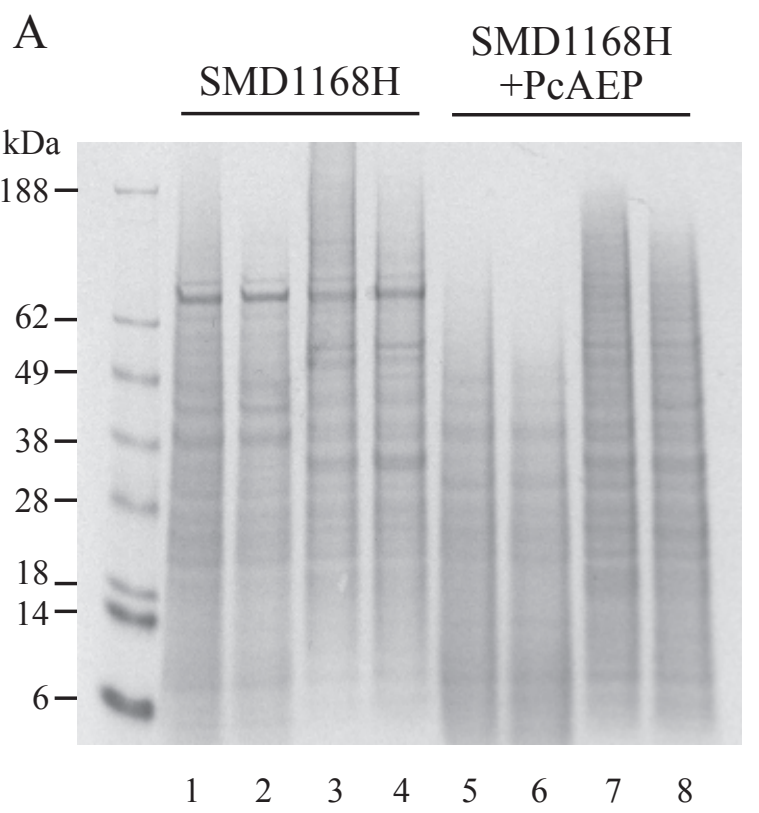

B

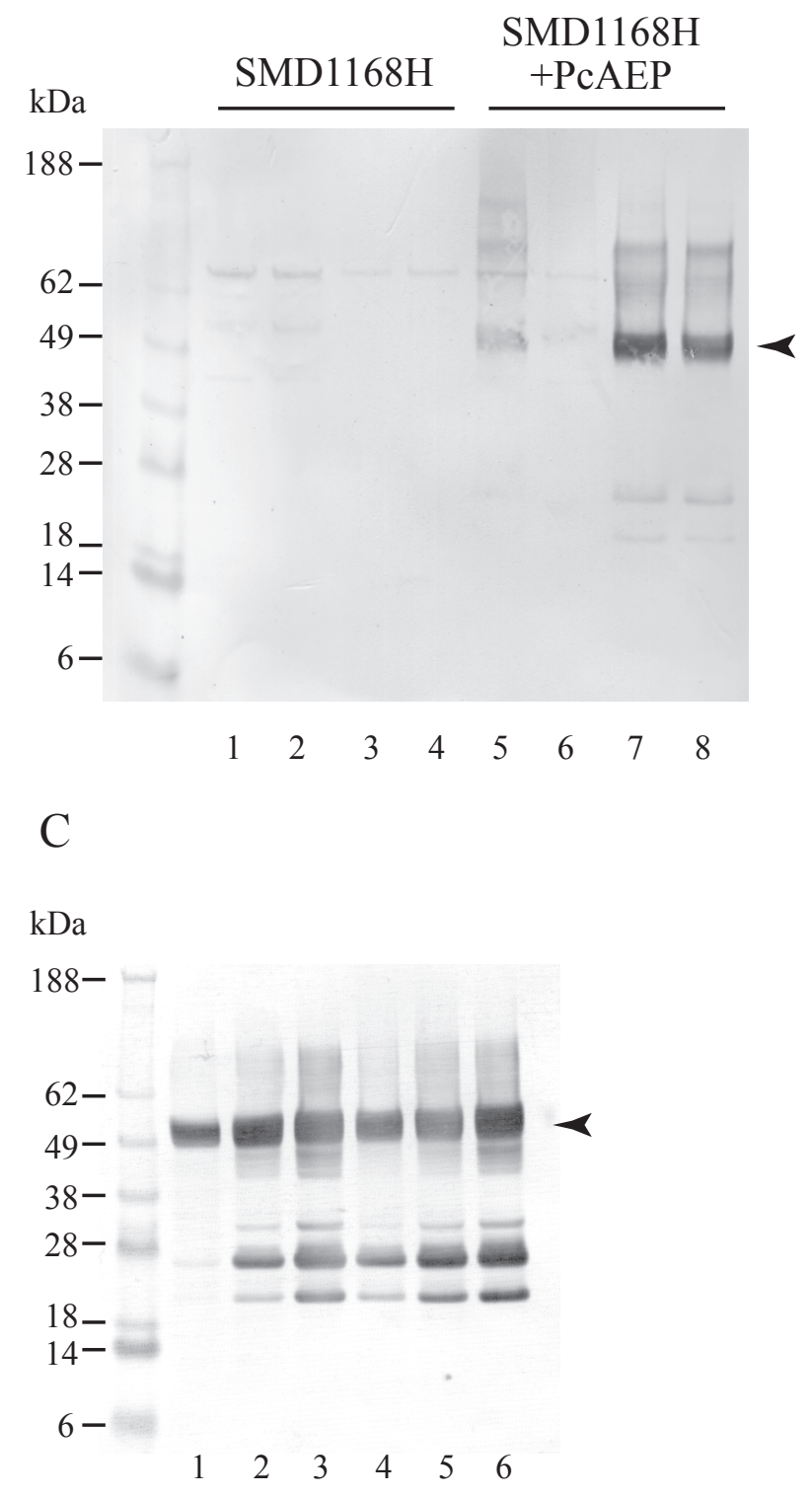


NP-40-

SMD1168H

a

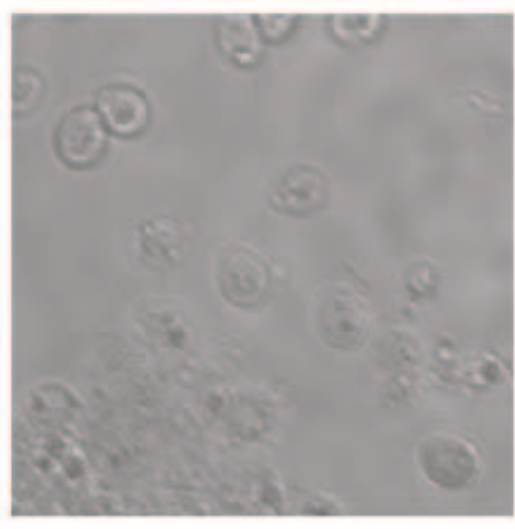

b

PcAEP

$\mathrm{N}$-terminal His-tag
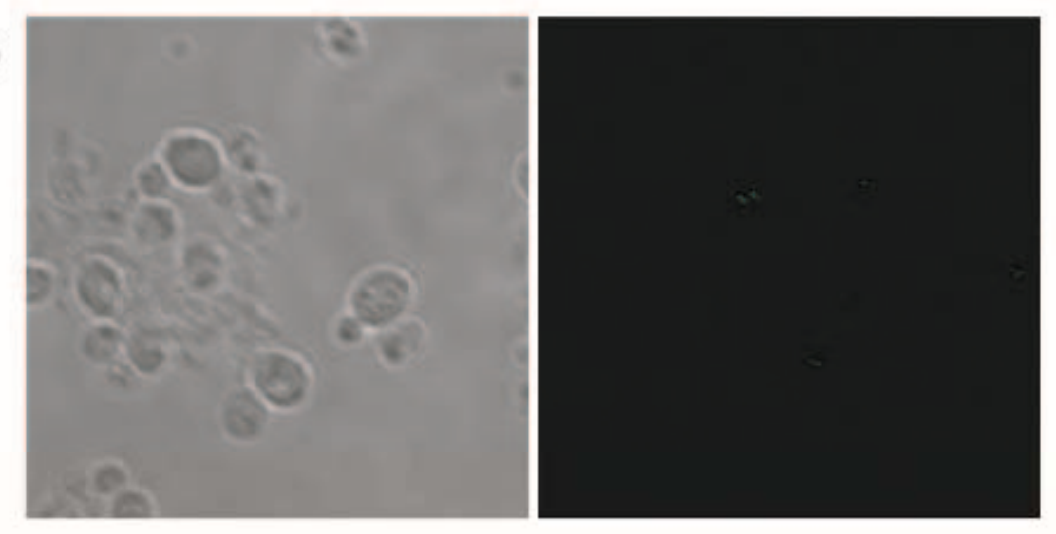

PcAEP

C-terminal His-tag e

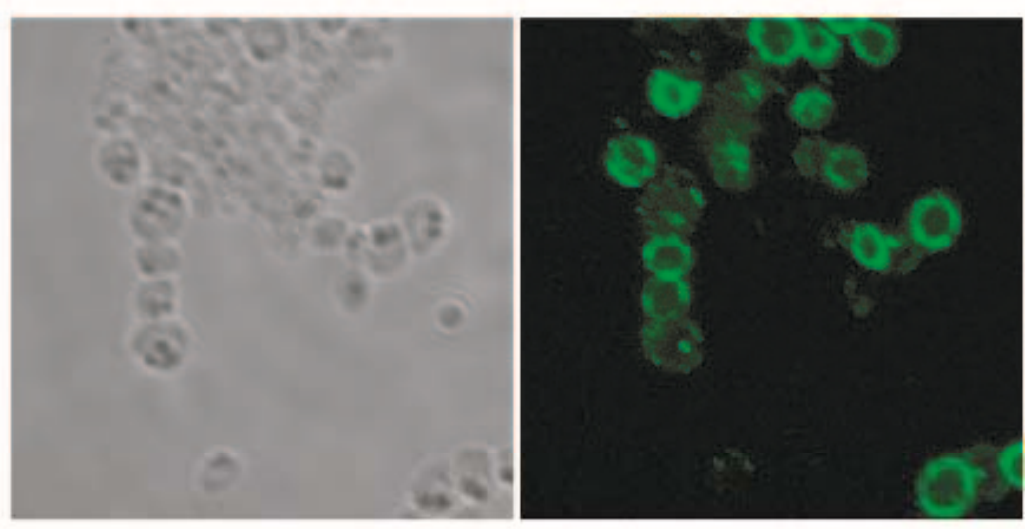

d

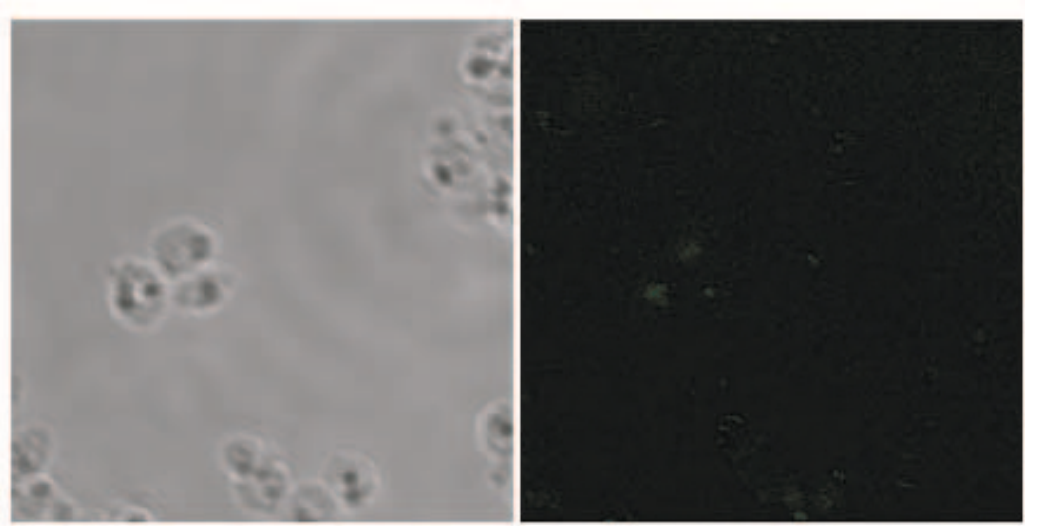

f

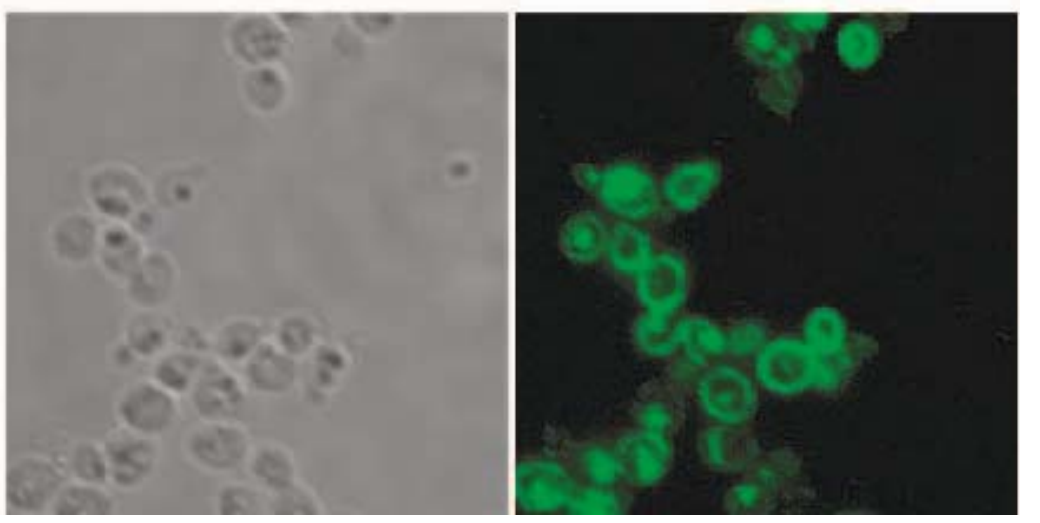

c

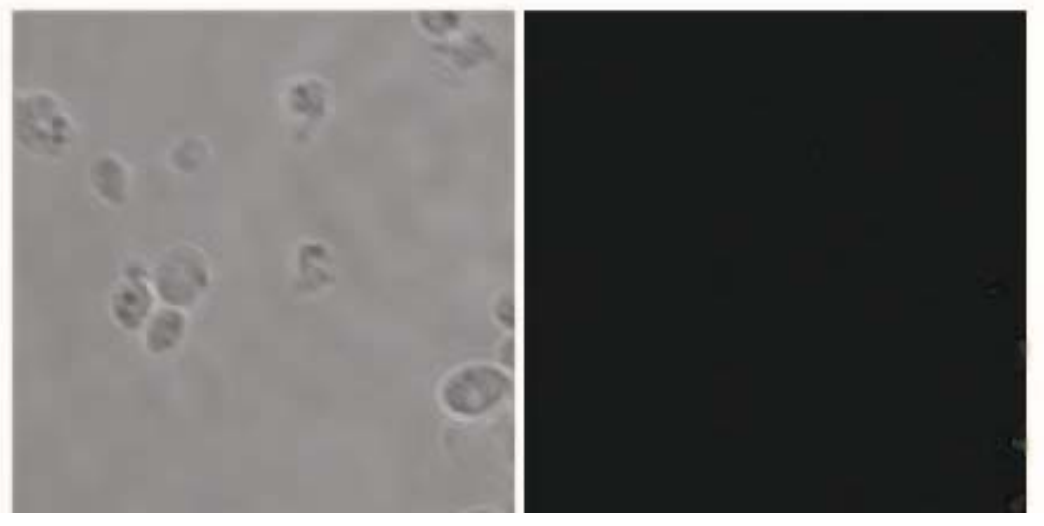


A

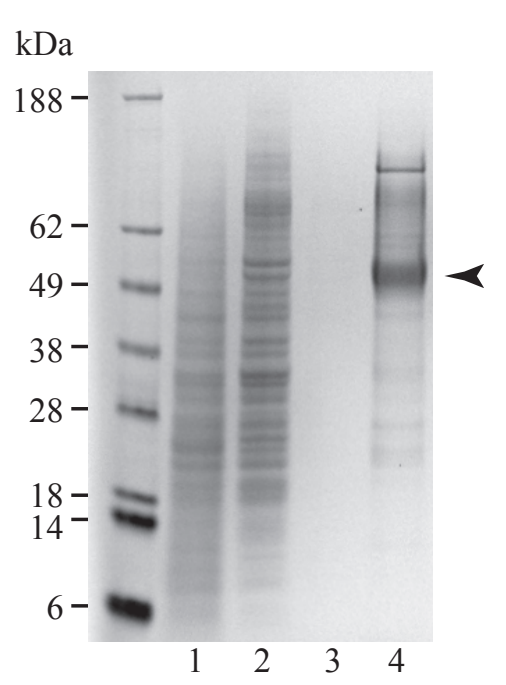

C

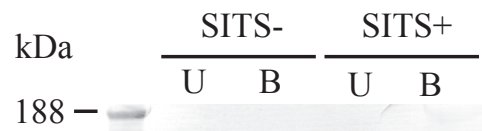

$62-$

$49-$

$38-$

$28-$

$18=$

$6-$

\section{B}

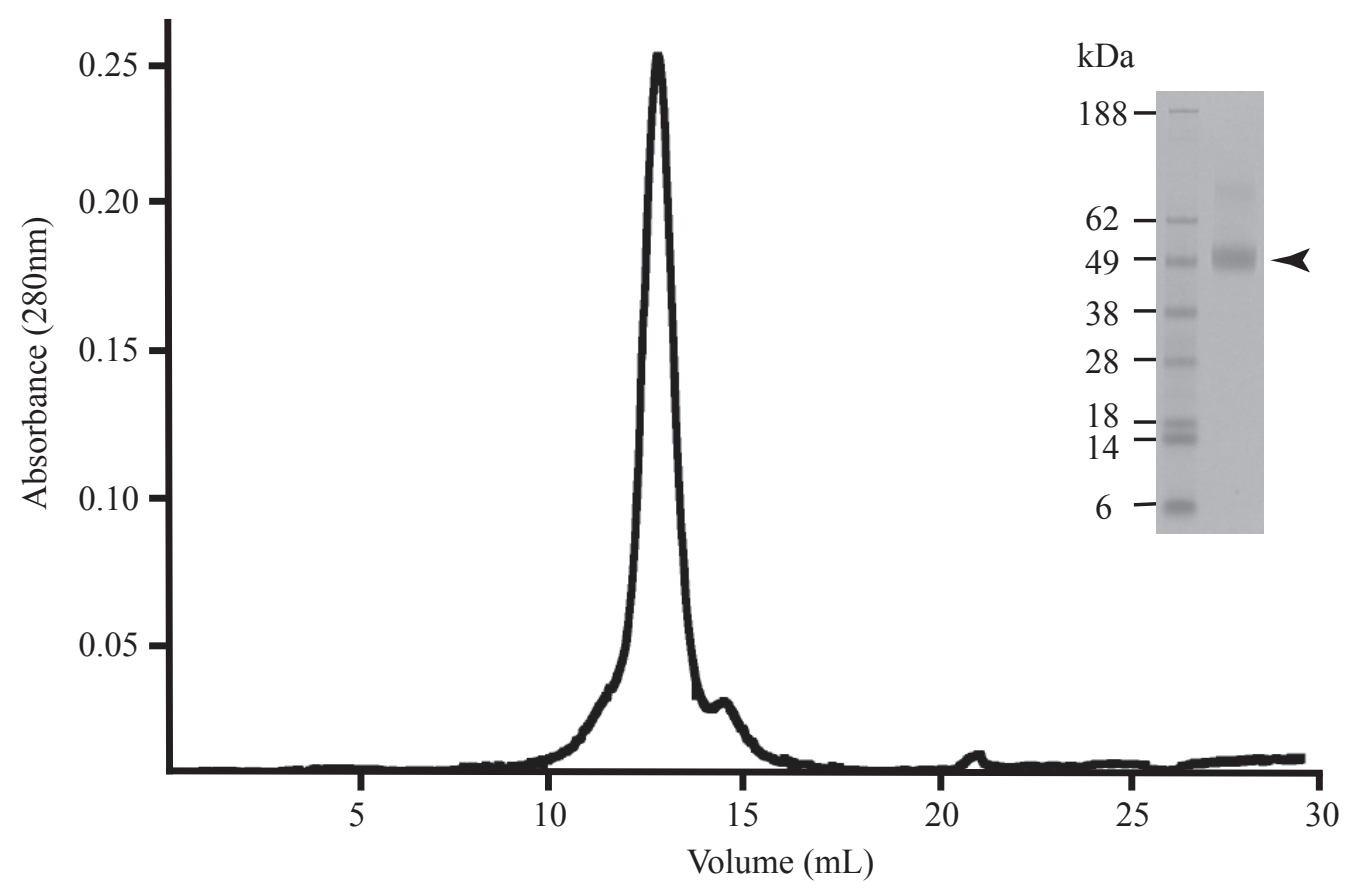

